\title{
ASPECTOS ACTUALES DE LA LITERATURA GRIEGA CLASICA
}

\begin{abstract}
The author of this paper offers a synoptic and critical view of different trends of criticism in the field of Ancient Greek Literature, specially Archaic Epic, Lyric, Tragedy and Historiography.
\end{abstract}

\section{Algunos estudios SObRe la epopeya arcaica}

Me atrevería a afirmar que los dos libros más importantes del siglo xx sobre Homero son, de un lado, el revolucionario trabajo de Milman Parry (L'épithète traditionnel dans Homère, París 1928) y los Iliasstudien de W. Schadewaldt (Leipzig 1938; reedición, Darmstardt 1966). El primero lanzó en el mundo científico una auténtica bomba que iba a modificar, ciertamente al cabo de algunos años de retraso, la perspectiva en que se mueve una parte de la investigación homérica (sobre todo, pero no exclusivamente, en el mundo anglosajón); el segundo resolvió, en gran parte, la cuestión homérica, por lo menos en aspectos muy importantes. En la dirección de Schadewaldt se ha movido predominantemente la investigación alemana.

El trabajo de Milman Parry demostró, de un modo inequívoco, que la primitiva poesía griega era una poesía formular, oral. Sus importantes puntos de vista han sido nuevamente empleados para el análisis de la poesía homérica - y hesiódica- por obra de una serie de críticos: Kirk (The Songs of Homer, Cambridge 1962). Notopoulos ( SStudies in early Greek oral Poetry», Harvard Studies in Class. Philology 68, 1964, p. 1 ss.), Lord (The Singer of Tales, Cambridge, Mass., 1960), Hoekstra (Homeric modifications of Formulaic Prototypes, Amsterdam 1965) se han destacado por su análisis, crítica, profundización de las fértiles ideas de Parry, y han replanteado la cuestión homérica sobre unas nuevas bases. El problema se plantea cuando el carácter oral de la 
poesía primitiva griega se aplica a la "redacción» de la Iliada y la Odisea (y, eventualmente, de Hesíodo, de los Himnos homéricos y el Ciclo épico). ¿Se trata de ver en la Ilíada y la Odisea unos poemas que han sido realmente elaborados de una forma improvisada, y transmitidos por vía oral? ¿Será más acertado ver en ellos unos poemas en los que se ha empleado la técnica oral, pero aplicándolos a unas obras redactadas, no improvisadas, dado que su extensión impide concebirlos como obras orales? ¿Se tratará de poemas "dictados»? Aquí, cada autor ha marchado por su propio camino, aunque, en general, en amplios círculos de críticos, parece haberse impuesto la tesis de una composición oral, con matices. Que la cuestión no está zanjada lo prueba el hecho de que recientemente (cf. A. Dihle, Homer-Probleme, Opladen 1970) se haya podido dirigir una dura crítica contra quienes quieren ver en los poemas homéricos no una obra escrita, complicada, e imposible, por su estructura, de ser concebida por mera tradición oral, sino que han debido ser poemas escritos, como delatarían, según dicho autor, las dificultades que surgen cuando se pretende ver en Homero a un mero poeta oral. Para Dihle el primer poeta que empleó el auxilio de la escritura fue Hesíodo. Pero la poesía épica anterior, la Iliada y la Odisea, aunque compuestas con la técnica oral propia de la epopeya heroica anterior, trascienden la pura oralidad. En todo caso, los partidarios de la poesía oral (cf. lo que decimos en el apartado dedicado a la lírica) han intentado extender el carácter oral e improvisado del epos a la misma lírica. La cuestión queda abierta.

En otra dirección se mueve la crítica alemana, por lo general, siguiendo los principios trazados por Schadewaldt en el libro antes mencionado. La escuela que este profesor de Tubinga fundó, y que ha recibido el nombre de Neoanálisis o Análisis Ilustrado, para diferenciarla de la de los analistas del siglo pasado que destruían la poesía a base de hallar en todas partes contradicciones, ha tenido importantes continuadores, tanto en Alemania (en especial W. Kullmann) como fuera de ella (Kakridis es el más importante: cf. su estudio Homeric Research, Lund 1949). El principio en que se basa la escuela neoanalítica es, de un lado, la afirmación de que el poeta de la Ilíada se ha servido de fuentes anteriores -orales seguramente- que ha sabido emplear muy inteligentemente (cf., del propio Schadewaldt, el artículo "Einblick in die Erfindung der Ilias", recogido en Vom Homers Welt und Werk, Stuttgart $1959_{3}$, duramente criticado por U. Hölscher en Gnomon). En los Iliasstudien, Schadewaldt realizó la enorme hazaña de demostrar que hay un arte homérico, caracterizado por la retardación y la anticipación (los conceptos proceden de Goethe), lo que delata, detrás de la obra, 
una personalidad literaria innegable. W. Kullmann ha continuado el camino de su maestro en dos libros fundamentales: Die Quellen der Ilias (Hermes, Einzelschrift 14, Wiesbaden 1960), y un librito anterior que plantea interesantes problemas (Das Wirken der Götter in der Ilias, Berlín 1956). La existencia de esta escuela neoanalítica no ha sido obstáculo para que aparecieran, en regiones de tradición germana, libros orientados en la línea del análisis del siglo xix (como Peter von der Muehll en su Kritisches Hypomnema zur Ilias, Basilea 1952, que postula la existencia de dos poetas detrás de la obra tal como ha llegado hasta nosotros. Lo mismo ha hecho para la Odisea en el art. de la RealEnzyklopädie de Pauly-Wissowa; cabe citar, asimismo, a R. Merkelbach, Untersuchungen zur Odyssee, Munich 19692). Militan asimismo en la escuela analítica W. Theiler, "Die Dichter der Ilias" (Festschrift Tièche, Berna 1947, p. 125 ss.), y, últimamente, H. van Thiel, Iliaden und Ilias, Basilea 1981.

Si descontamos la "cuestión homérica», ¿por dónde discurren los problemas actuales en torno a Homero y el epos arcaico en general? La lectura de los dos poemas despierta, al tiempo, dos sensaciones contrapuestas: la de una gran unidad general, pero, también, la de una importante diversidad entre los dos. Esta impresión ha sido muy bien expresada por R. Friedrich (Stilwandel im homerischen Epos, Heidelberg 1975, p. 1) con estas palabras: "Una experiencia típica del lector de Homero que, tras la Ilíada, se acerca a la Odisea, es la impresión de que el poema más reciente es semejante y, sin embargo, distinto, y que artísticamente es independiente pero en cierto modo dependiente de aquél». Precisamente uno de los puntos capitales de la Homerología es el problema de determinar las relaciones existentes entre los dos poemas. Hay rasgos que apuntan a una dependencia de la Odisea respecto de la Ilíada, y otros que apuntan a la constitución de un epos original. Varias tesis se han avanzado para exponer y solucionar la cuestión:

a) W. Diehl (Die wörtlichen Beziehungen zwischen Ilias und Odyssee, Greifswald 1938) ha señalado no pocos casos en los que el poeta de la Odisea "cita" la Ilíada. Son versos repetidos en los dos poemas, y suele estarse de acuerdo en que los de la Ilíada son anteriores a los de la Odisea. Sólo muy pocos críticos sostienen que ésta es anterior a aquélla (por ejemplo, Patroni, Commenti mediterranei all'Odissea di Omero, Pavía 1950).

b) La mayor calidad literaria de la Iliada frente a la Odisea (argumento un tanto subjetivo y discutible, pero que, en líneas generales, puede aceptarse y así suele hacerse) suele ser otro argumento en favor 
de la mayor antiguiedad de la Iliada, aunque no faltan quienes sostienen lo contrario (una lista en Heubeck, Der Odyssee-Dichter und die Ilias, p. 12 ss.).

c) En otras ocasiones se aduce la profunda diferencia de estilo y de pensamiento para hacer a la Odisea posterior a la Iliada: K. Deichgräber (Eleusinische Frömmigkeit und hom. Vorstellungswelt im hom. Demeterhymnus, Mainz 1950) ha señalado las diferencias ideológicas; Reinhardt (Tradition und Geist, p. 123 ss.); Fränkel destaca el "gran realismo y la mayor proximidad a la vida real» de la Odisea; F. Jacoby ( $«$ Die geistige Physiognomie der Odyssee $=$ Kleine phil. Schriften, Berlín 1961, p. 167 ss.) hace notar que en la Odisea falta la tensión dramática que domina toda la Ilíada; Kakridis (Homeric Research, Lund 1949, p. 4) califica la Iliada de epos dramático, la Odisea de epos geográfico (de aventuras, podríamos decir). Finalmente el libro antes mencionado de R. Friedrich (Stilwandel im hom. Epos), partiendo de que hay en la Odisea un "epos de nuevo estilo", intenta hallar, con criterios objetivos, los rasgos que hacen efectivamente un poema distinto de otro.

En todo caso, hay que recalcar el hecho de que el problema de las semejanzas y desemejanzas entre los dos poemas "homéricos» se ha orientado, últimamente, hacia una perspectiva muy interesante, consistente en señalar los rasgos más representativos del "tipismo" iliádico y ver hasta qué punto es aplicable a la Odisea. Así, Heubeck, en el libro antes citado, ha puesto de relieve cómo la técnica narrativa de la Odisea -dos acciones independientes que al final se juntan (Telémaco y sus andanzas y Ulises y sus aventuras)- está claramente inspirada en la técnica - muy parecido y sin duda modelo para el poeta odiseico- del libro XXIV de la Iliada: las acciones independientes de Príamo y de Aquiles, que al final coinciden en la tienda de éste.

Pero los estudios más importantes son los que intentan ir a una definición comprehensiva del concepto de aristía (un héroe se distingue de los demás en la lucha, protegido por una divinidad), para ver cómo el poeta odiseico lo ha aplicado en su poema, trasladando un recurso típicamente iliádico. Así, T. Krischer (Formale Konventionen der homerischen Epik, Munich 1971) ha llevado a cabo un estudio minucioso del concepto de aristía, así como su estructura tal como es empleada en la Iliada, aplicándolo a la Odisea. Ya antes se habían realizado aproximaciones parecidas: así, a principios de siglo H. Jordan (Der Erzählungstil in den Kampfszenen der Ilias, Diss. Zurich 1904) fue uno de los primeros en señalar que las escenas de batalla en la Ilíada responden a unas estructuras que se repiten a lo largo del poema (más tarde Friedrich, Verwundung und Tod in der Ilias, Gotinga 1956, volvió 
sobre el tema, pero para plantearlo desde otras perspectivas). En 1933, Arend (Die typischen Szenen bei Homer, Berlín), al estudiar el «tipismo» de las escenas homéricas (salida y puesta del sol, banquetes, etc.) insistió en el mismo hecho, pero, dada la pequeña extensión del trabajo, sólo puede referirse de paso a la cuestión. Este tipismo de las escenas de batalla homéricas ha vuelto a ser estudiado por B. Fenık (Typical battle-scenes in the Iliad, Wiesbaden 1968), que llega a la conclusión - que podemos considerar prácticamente definitiva- de que "la técnica de composición de las escenas de batalla está relacionada con la composición de cada verso" (p. 229, aludiendo al estilo formulario del verso homérico). Ese mismo carácter típico de la poesía homérica lo hallaremos asimismo en la cuestión de las comparaciones, ese elemento tan característico de la poesía homérica (cf. W. C. Scott, The oral nature of the Homeric Similes, Leiden 1974). Por un camino parecido discurre un trabajo de D. Lohmann, Die Komposition der Reden in der Ilias, Berlín 1970.

Volviendo al concepto de aristia, Krischer ha señalado los rasgos característicos: el héroe es impulsado por una divinidad que llena su thymós de ménos (empuje guerrero, locura bélica); se describe el brillo de sus armas, su marcha al combate, sus encuentros con una serie de guerreros, anónimos o no, para acabar enfrentándose con algún héroe principal, al que abate o hiere; inmediatamente se lucha por rescatar el cuerpo de este guerrero caído; finalmente el áristos (el guerrero combatiente y victorioso) se retira, tras alcanzar la "fama» (kléos), o cae herido, a veces de muerte (como Patroclo). Rasto específico es que una divinidad protege al héroe a lo largo de su combate, llegando a veces (como Diomedes en el canto V) a enfrentarse, en su empuje, a la misma divinidad que se le enfrenta. Pero, a pesar de ese esquematismo, hay una técnica de la variación de los elementos estructurales. En caso contrario, la Ilíada sería un poema de insoportable lectura. Pero, como dice Krischer, "de no haber variantes en el esquema general, los héroes homéricos se parecerían demasiado entre sín.

Vista así, la Iliada es como una enorme aristia. Antes del trabajo de Krischer, algunos estudios se habian ya ocupado del problema: en 1956, Kullmann, al estudiar la acción divina en relación con el hombre (Das Wirken der Götter in der Ilias, Berlín) abordó los rasgos de la epifanía divina. Antes, R. Schröter en un trabajo inédito (Die Aristie als Grundform epischer Dichtung und der Freiermord der Odyssee, Diss. Marburgo 1950) califica ya la muerte de los pretendientes como auténtica aristía. Dando un paso más, M. Müller (Athene als göttliche Helferin in der Odyssee, Heidelberg 1966) señala que, con un cambio en 
el concepto de aristia (la excelencia del héroe se manifiesta por el hecho de que, con la ayuda divina, Ulises sale siempre vencedor de sus empresas) puede ponerse la Odisea al mismo nivel de la Iliada. Sólo ha habido una trasposición del campo de la guerra al de la vida.

De entre los restantes problemas relativos a la poesía homérica reseñaremos, muy brevemente, el trabajo de B. Hellwig (Raum und Zeit im hom. Epos, Diss. Tubinga 1962, publicada luego en Spudasmata), que se ocupa del sentido y empleo que hace Homero de tiempo y espacio. En esta misma dirección se han movido D. Page (The homeric Odyssey, Oxford 1955) y Ed. Delebecque (Télémaque et la structure de l'Odyssée, Aix-en-Provence 1958), que han estudiado la llamada "ley de sucesión épican: al no poder tratar el poeta simultáneamente lo que ocurre simultáneamente, se produce la impresión de que hay «tiempos muertos" en el poema.

Fuera ya de los problemas técnicos, se han abordado algunos aspectos "ideológicos»: así A. Lesky, en su estudio Göttliche und menschliche Motivation im hom. Epos (Heidelberg 1961, cf. mi reseña en EMERITA 31, 1963 , p. 165 ss.), ha planteado el problema que se plantea cuando en Homero vemos que una acción humana es vista desde dos ángulos de enfoque: el humano y el divino. Parece que hay dos motivaciones en los actos humanos. Como es sabido, Dodds se ha ocupado de la misma cuestión (ya antes Nilsson), acunando el concepto de "superdeterminación” (Los griegos y lo Irracional, trad. cast., Madrid 1960). Finalmente, aunque el libro lleva ya algunos años publicado, el trabajo de F. Buffière (Les mythes d'Homère et la pensée grecque, Paris 1956) ha seguido paso a paso las diversas interpretaciones alegóricas que de Homero se han producido en la antigüedad, tema que han abordado también en otras perspectivas Pépin (Mythe et allégorie, París 1965) y P. Levècque (Aurea catena Homeri, Paris 1969). Sobre el libro de Buffière cf. mi reseña en EMERITA 25, 1957, p. 257 ss.

Hesíodo ha sido objeto, en los últimos años, de notables estudios. De un lado, es evidente que la teoría de la literatura oral tenía que proyectarse sobre este autor. Y, en efecto, ha sido analizado desde este punto de vista por varios autores. Uno de los más recientes (tras los estudios parciales de Hoekstra ["Hésiode et la tradition orale», Mnemosyne, 1957, p. 193 ss.], Krafft [Vergleichende Untersuchungen zu Homer und Hesiod, Gotinga 1963], Notopoulos [Hesperia 29, 1960, p. 177 ss.] y Kirk ["The structure and aims of the Theogony" en el vol. VII de los Entretiens sur l'Antiquité, Vandoeuvres-Ginebra 1962, p. 61 ss.]), es el de G. P. Edwards, The language of Hesiod in its traditional context, Oxford 1971. 
Un buen barómetro para comprobar los temas hesiódicos que interesan hoy son los dos volúmenes colectivos dedicados a este poeta: uno, el antes mencionado de la Fundación Hardt, donde se discuten problemas como el elemento personal hesiódico en su obra (K. von Fritz), intención y estructura de los Trabajos y los dias (Verdenius), entre otros, y el editado por E. Heitsch, en la colección «Wege der Forschung» (Hesiod, Darmstadt 1966), mucho más amplio y ambicioso. Aquí se abordan una serie de problemas que son hoy candentes: la "cuestión hesiódica", la forma de la Teogonia, de los Trabajos, el mito y el influjo de oriente sobre las narraciones hesiódicas, etc. Los "problemas sociales" los hemos abordado más adelante, analizando los estudios de Detienne, E. Will, Solmsen, etc.

Una breve referencia, para terminar, al libro de conjunto de L. G. Huxley, Greek Epic Poetry. From Eumelos to Panyasis, Londres 1969 , que es un bien logrado intento por analizar la poesía épica de tendencia heroica posterior a "Homero", y el opúsculo (76 páginas) de A. Hoekstra, el fino exégeta de las fórmulas homéricas, "The Sub-Epic Stage of the Formulaic Tradition" (Verhandl. Kon. Nederl. Akad. van Wet., Afd. Letterkunde, LXXV, n." 2), Amsterdam 1969, que aborda los Himnos homéricos intentado contestar a la pregunta de si debido a las modificaciones de las fórmulas homéricas introducidas en esos himnos permite llamar, a este estadio, sub-épico, como los calificó Allen. Ataca, concretamente, a Reinhardt, sobre todo su tesis de que el Himno a Afrodita es el más homérico de la colección (cf. K. Reinhardt, Die Ilias und ihr Dichter, Gotinga 1961, p. 507; y Heitsch, Aphroditenmythos, Aeneas und Homer, Gotinga 1965, que quiso ampliar y justificar la tesis de Reinhardt. Hoekstra, tras su análisis, afirma rotundamente (p. 45), que «no debe repetirse, ya que el Himno a Afrodita es, con mucho, el más homérico". "Su dicción - añade- representa un estadio posterior en la evolución poética».

\section{I. La l.́RICA ARCAICA EN ta CRITICA ACTUAL.}

El libro más importante que ha aparecido en los últimos decenios, tras el importante trabajo de Bowra sobre la lírica (Greek Lyric Poetry, Oxford 1936), es, sin duda, el imponente estudio de H. Fränkel (Dichtung und Philosophie des frühen Griechentums, Nueva York 1951, Munich $19622_{2}$, trad. inglesa Nueva York-Londres 1975). El impresionante estudio del gran filólogo germánico, pese a las innegables críticas a que puede ser sometido (sobre todo véase la amplísima reseña que le dedica 
Gundert en Gnomon 27, 1955, p. 465 ss.), es un punto de arranque que deben tener en cuenta todos los intentos por estudiar la época arcaica. Orientado a buscar, más que el proceso, el ritmo que domina en la historia de la literatura griega temprana, fruto de importantes estudios anteriores (algunos recogidos en Wegen und Formen frühgr. Denkens, Munich 1955), consagra la mayor parte de la obra a la lírica, cuya aparición - junto con las posibles causas que puedan explicarla- es debida a que el hombre arcaico descubre el carácter lábil, efímero, de la existencia humana. Por las mismas fechas en que se está gestando el libro de $\mathrm{H}$. Fränkel aparecen una serie de interesantes estudios que vienen a confluir en la temática general abordada por este autor: el descubrimiento de la personalidad (Snell, Die Entdeckung des Geistes, Hamburgo 1948), los intentos de A. Heuss por hallar el sentido histórico de la época arcaica (Antike und Abendland, II, 1946), la profundización del sentido de "propiedad" de la obra, frente al anonimato de la épica (W. Kranz, "Sphragis: Ichform und Namensiegel als Eingangs- und Schlussmotiv antiker Dichtung», en Studien zur antiken Literatur, Heidelberg 1967; el trabajo apareció en 1961). La "escuela alemana» se orienta esencialmente hacia lo que llaman los críticos Geistesgeschichte (término que suele traducirse, inexactamente, por "historia de las ideas»), orientación que han seguido, en buena parte de sus trabajos, críticos de la categoría de W. Jaeger (Paideia), M. Treu (Von Homer zur Lyrik, Munich 1955) y R. Pfeiffer ( $\propto$ Gottheit und Individuum in der frühgr. Lyrik», Philologus 84, 1929, p. 132 ss.), entre los más significativos (el libro más representativo es, quizá, el de W. Nestle, Griechische Geistesgeschichte, del que hay trad. castellana con el título de Historia del espiritu griego, Barcelona 1961).

Orientación muy distinta, en cuanto, por un lado, niega lo que cabría llamar el progreso en la evolución de las «ideas", y, por otro, sienta las bases de una concepción de la literatura arcaica como o r a l, sigue la escuela anglosajona, apoyada por las investigaciones de los italianos, en especial $\mathrm{Br}$. Gentili. Típico de la oposición a la "historia de las ideas" es el libro de H. Lloyd-Jones The Justice of Zeus, Berkeley 1971, que concede una gran importancia a lo arcaico, aunque se ocupa asimismo de la época clásica. Quien ha dado un mayor impulso a la tesis del carácter oral de la época arcaica -e incluso en parte de la clásicaha sido Havelock, en su libro Preface to Plato, cuya traducción italiana lleva un título más indicativo de la temática abordada en la obra (Cultura orale e civiltà della scrittura, Bari 1973). Ha sido precisamente Gentili quien, junto con sus discípulos, con mayor intensidad se ha ocupado de abordar el estudio de lo arcaico a partir de esa nueva con- 
sideración. El órgano de expresión de esa corriente es la revista Quaderni Urbinati di cultura classica. De Gentili son algunas trabajos que abordan este interesante tema. Citemos su artículo «L'interpretazione dei lirici arcaici nella dimensione di nostro tempo» (Quad. Urb., 1969, p. 9 ss.) o el capítulo «Lirica greca arcaica e tardo arcaica» en el libro Introduzione allo studio della cultura classica (I, Letteratura, Milán 1972, p. 57 ss.). El descubrimiento del carácter oral y formulario de la poesía homérica realizado por M. Parry en 1928 (L'épithète traditionnel dans Homère) ha sido nuevamente valorado a partir de los años cuarenta (e incluso su teoría del lenguaje formulario ha sido aplicada a la lírica arcaica). Han surgido, así, una serie de importantes estudios, como los de T. G. Rosenmeyer "The formula in Early Greek Poetry" (Arion 4, 1965, p. 302 ss.) y Giannini «Espressione formularia nell'elegia greca arcaicas (Quad. Urb., 1973, p. 1 ss.), aunque la presencia de homerismos había sido ya detectada mucho antes, pero su interpretación era distinta de la que le dan los críticos actuales (en especial cf. $\mathrm{O}$. von Weber, Die Beziehungen zwischen Homer und den älteren gr. Dichtern, Diss. Bonn 1955). Importante es el estudio dedicado, en este aspecto, a Arquíloco por parte de D. Page («Archilochus and the Oral tradition", en el vol. X de los Entretiens sur l'Antiquité dedicado a Arquíloco, Vandoeuvres-Ginebra 1964, p. 117 ss.), contra muchos de cuyos argumentos se ha vuelto últimamente $A$. Dihle en su libro Homer-Probleme, Opladen 1970, p. 48 ss.).

La aplicación del carácter tradicional y formulario a la poesía arcaica ha permitido a C. O. Pavese intentar una nueva clasificación de los géneros literarios arcaicos (Tradizioni e generi poetici della Grecia arcaica, Roma 1972). Resultado de anteriores estudios del propio autor, en este trabajo aborda la cuestión de si es posible distinguir dos tradiciones épicas y líricas - que es lo que aquí nos interesa- en la Grecia arcaica. Su contestación es afirmativa: distingue, en efecto, Pavese dos grandes tradiciones: de una parte, la tradición meridional (miceneo-jónica), de otra, la septentrional, representada por Hesíodo, algunos himnos homéricos, Tirteo, Teognis, la lírica de Lesbos y la poesía coral. Ambas tradiciones se habrían influido mutuamente, lo que explicaría la presencia de "pretendidos jonismos» en Homero. La tesis de Pavese ha sido sometida a una dura crítica por V. Cassadio (cf. Gnomon 49, 1977, p. 446 ss.).

Si nos ocupamos, ahora, de algunos libros en concreto sobre la lírica arcaica, comenzaremos por dar una cierta primacía a los recientes trabajos de F. R. Adrados enfocados hacia el proceso de formación de la lírica arcaica a partir de la poesía ritual (Los origenes de la lírica 
griega, Madrid 1976), hacia el análisis de los contenidos y tendencias que pueden descubrirse en los poetas arcaicos ( $E l$ mundo de la lirica arcaica, Madrid 1981) o bien a la reinterpretación de los fragmentos (Lírica griega arcaica, Madrid 1980). Un buen estudio, de conjunto, sobre el período preclásico (o tardo-arcaico) es el libro de Fr. Schachermeyr Die frühe Klassik der Griechen, Stuttgart 1966.

Por lo que respecta, concretamente, a Tirteo, hay que mencionar, de entre los más curiosos estudios últimamente aparecidos, el de $\mathrm{Br}$. Snell Tyrtaios und die Sprache des Epos (Gotinga 1969): partiendo de sus ideas básicas inspiradas en la concepción de las relaciones lenguajepensamiento que defendieron Humboldt y Herder, Snell - que ha aplicado este método en algunos de los capítulos dedicados al tema en su trabajo ya citado, Die Entdeckung des Geistes (del que existe traducción castellana: Las fuentes del pensamiento europeo, Madrid 1965)acepta en bloque la autenticidad de los fragmentos tirteicos; lo que le interesa, fundamentalmente, es rastrear las posibles "innovaciones" del poeta en relación con la lengua del epos homérico. Lo genuinamente tirteico es buscado por Snell en el uso de los términos thymós y psychê, sosteniendo que, en el empleo de tales términos, comprobamos en el elegíaco un desplazamiento semántico; también halla innovaciones en

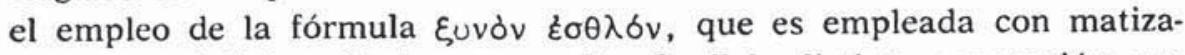
ciones en el lírico; finalmente analiza Snell la distinta concepción que hallamos en Tirteo de las vocaciones humanas. En conclusión, las innovaciones que descubre Snell en Tirteo se distinguen de las que podemos descubrir en Alceo y Safo, por ejemplo, mucho más profundas y de mayor alcance. Tirteo se ha limitado a ciertos desplazamientos semánticos, a matizaciones de los términos homéricos.

Aspectos curiosos analiza $\mathrm{H}$. Schmitz sobre el conjunto de la poesia arcaica en su librito Hypsos und Bios: Stilistische Untersuchungen zum Alltagsrealismus in der arch. gr. Lyrik (Berna 1970). La proximidad de la "vida" y la poesía en la época arcaica - en su primera etapa- es la tesis básica de $\mathrm{H}$. Fränkel en su ya mentado libro. Pero aunque la idea había sido lanzada, muy pocos trabajos se habían dedicado a profundizar el tema. Descartando un curioso estudio de W. Theiler que intentaba descubrir una mayor intensidad de realismo en las odas de la segunda época pindárica (Die zwei Zeitstufen in Pindars Stil und Vers, aparecido en 1941 y reproducido en Untersuchungen zur antiken Literatur, Berlín 1970, p. 148 ss.; libro que ha sido muy duramente criticado últimamente por S. Fogelmark, Studies in Pindar, Lund 1972, y ya antes por Dornseiff), puede decirse que el tema era virgen. Schmitz ha intentado profundizarlo, pero la brevedad de su estudio hace que 
queden muchos puntos sin resolver. Por lo pronto, el autor entiende por realismo no lo que por ello se entendió en el siglo xIX; para Schmitz, se trata de la penetración de la vida cotidiana (Alltagsrealismus) en la literatura arcaica. En eso, como en otras cosas, es, pues, fiel a los puntos de vista de Fränkel. Frente a esta "cotidianidad" se alza la literatura «elevada» (Hypsos): el problema es estudiar cómo se compaginan estos dos elementos en la lírica arcaica. Se analizan en el libro los fragmentos de Alcmán, Estesícoro y Simónides, dentro de la lírica coral prepindárica. En este apartado incluye a Baquílides -claramente postpindárico, o al menos, contemporáneo más joven del poeta-. Pero es que, para el autor, "Baquilides, en su talante poético, sigue las huellas de la poesía tradicional prepindárica» (p. 20). Una sección entera es consagrada a Píndaro, con especial referencia al tratamiento que el poeta da a las mujeres, y, además, planteando el problema de si es posible distinguir diferencias estilísticas dentro de los distintos géneros tocados por el poeta. Las conclusiones del autor son muy matizadas: por lo que a Alcmán se refiere, halla que los medios y los recursos del "estilo elevado" no le son desconocidos, pero que, aun a pesar de que a cada instante su canto se remonta hacia las alturas, el poeta es incapaz de permanecer en él. Constantemente aparecen elementos "cotidianos". En Simónides encuentra una cierta tendencia a representar las cosas como son. En lo que atañe a las descripciones de los hechos "horribles", no deja de anotar Schmitz que "algunos fragmentos muestran la transformación del realismo en una fantasía brutal" (así en Estesícoro, fr. 219 P., donde la cabeza ensangrentada de la serpiente se convierte en el príncipe Plístenes). Por lo que atañe a Baquílides, apunta el autor que en la narración mítica "no hallamos nada puramente biótico".

En el capítulo de los elementos formales de la lírica arcaica hemos de destacar el trabajo de R. Führer Formprobleme-Untersuchungen zu den Reden in der frühgr. Lyrik, Munich 1967. Las diferencias existentes entre Homero y la lírica, no en el mero campo formal, sino conceptual, habían sido ya tocadas por M. Treu (Von Homer zur Lyrik, Munich 1955). Führer, en cambio, orienta su trabajo en la más pura tradición filológica. Su finalidad concreta es el análisis de la estructura de los "discursos» en la lírica arcaica, sobre todo en lo que concierne a las fórmulas de introducción y cierre de tales discursos, y ver en qué medida se acercan o se apartan del uso homérico.

Arquíloco ha sido objeto de importantes estudios en los últimos quince años. Y ello por dos razones: de un lado, el descubrimiento de nuevos fragmentos ha estimulado a los críticos a una profundización 
de su poesía. Nos ocuparemos luego de este aspecto; pero acaso más importante sea el análisis que se ha intentado tanto de su figura como hombre de su tiempo, como de parte de su obra, y, en especial, de hasta qué punto es deudor $-\mathrm{y}$ en qué medida - de la tradición épica que le precedió. Dentro de este último aspecto, hay que mencionar el breve estudio de Th. Breitenstein, Hésiode et Archiloque (Odense 1971): el problema de las relaciones entre Hesíodo y Arquíloco ha sido casi siempre resuelto en sentido afirmativo, es decir, con la tesis de que el poeta de Paros ha recibido una serie de influjos concretos del de Ascra. En algunos casos (como Crusius) se ha llegado incluso a afirmar que Hesíodo es, sin más, un precursor de Arquíloco, sobre todo atendiendo a los aspectos "satíricos" y al elemento "personal» que domina en Los trabajos y los dias, aunque hay que decir que no hay acuerdo sobre la historicidad del pleito de Hesíodo con su hermano Perses. Es, pues, opinión generalizada en el siglo xx (W. Schmid, F. Jacoby, G. Perrotta, C. Gallavotti) que en el lírico hay importantes rasgos hesiódicos. Pero empieza, desde hace algún tiempo, a notarse la aparición de la tesis contraria: así, en su libro Hesiod and the Near East (Cardiff 1966), Walcot ha llegado a sostener que no hay datos concretos que permitan afirmar, sin sombra de duda, que Arquíloco hubiese conocido la obra de Hesíodo. La razón de la, al menos aparente, comunidad espiritual entre Hesíodo y Arquíloco sostenida por algunos filólogos se debe a la tendencia a ver en el poeta de Ascra un elemento "revolucionario" (así, Pöhlmann). Frente a tal actitud apunta hoy una cierta tendencia a rebajar bastante esta visión: en 1963 M. Detienne afirmaba taxativamente, en su opúsculo Crise agraire et attitude religieuse chez Hésiode (Bruselas 1963, p. 60), que no se puede sostener, sin más, la tesis de un Hesíodo reformador social. En 1965 E. Will, en una revisión del libro de Detienne ( $R E G 78,1965$, p. 549 ss.), seguía un camino parecido -no sin atacar algunos de los puntos de vista del mentado estudioso-, lo mismo que hemos hecho nosotros (cf. Literatura griega: contenido, problemas y métodos, Barcelona 1967, p. 208 ss.). Tal postura había sido ya anticipada, en cierto modo, por estudiosos como van Groningen, R. Martin y Sinclaire. El estudio más completo, hasta la fecha, de este problema es el de V. Steffen ( De Archilocho quasi naturali Hesiodi aemulatore», Eos 46, 1952/53, p. 33 ss.), pero el trabajo está viciado por una serie de puntos más que débiles: lo considera, como era normal hace varios lustros, un poeta revolucionario, $y$, lo que es peor, hay en el trabajo importantes lagunas bibliográficas. El opúsculo de Breitenstein ha intentado corregir los defectos y los puntos obscuros de la cuestión, llegando a algunas conclusiones interesantes: el trabajo 
del filólogo danés está muy bien documentado ( 340 notas en un total de 58 páginas), sabe aprovechar el nuevo material que se ha ido descubriendo y que aporta mucha luz sobre la vida y el contorno social del poeta de Paros (sobre todo las inscripciones del Arquiloqueo de Paros). Con esos resultados a la vista, Breitenstein sostiene que el prólogo de la Teogonía ha ejercido un notable influjo sobre ciertos aspectos de la poesía de Arquíloco (la epifanía de las Musas ha ejercido su influencia sobre la noción de misión en el poeta de Paros, cf. p. 58). Pero, pese a esas innegables inlluencias, los dos espíritus eran demasiado distintos para que uno haya tomado mucho material y mucha inspiración del otro. "Creemos -escribe el autor- que las ideas morales y religiosas de Hesíodo eran conocidas de Arquíloco; pero en cambio no compartía su concepto de la justicia divina.»

Una buena piedra de toque para percibir las nuevas rutas por las que discurre la moderna investigación sobre Arquíloco $-\mathrm{y}$, por ende, sobre el sentido último de su poesía- nos lo puede ofrecer el volumen $\mathrm{X}$ de los Entretiens sur l'Antiquité classique, publicados por la Fondation Hardt, de Ginebra, dedicado a este poeta (1964): aquí, figuras como Pouilloux y Contoléon han modificado profundamente la idea que ha predominado entre los estudiosos de una isla de Paros miserable y de un Arquíloco emparedado entre su procedencia noble (por parte de padre) y el hecho de que su madre era - se creía que erauna esclava. En cuanto a la poesía de Arquíloco, con sus profundos acentos personales, Dover ha intentado, en este mismo volumen, minimizarlos, intentando demostrar - a base de paralelismos con otras literaturas- cómo la canción popular suele ser anónima y hay en ella unos elementos constantes que podrían redescubrirse, asimismo, en Arquíloco.

La fragmentaria obra de Arquíloco ha sido objeto de innúmeros estudios, sobre todo cuando se trata de reconstruir el contenido de los Epodos. Hay que mencionar aquí, por un lado, el estudio de F. Lasserre (Les épodes d'Archiloque, París 1950), cuyas conclusiones han sido, posteriormente, corregidas por un trabajo de Adrados, «Nueva reconstrucción de los epodos de Arquíloco", aparecido en EMERITA (1955) y reproducido en El mundo de la lírica arcaica, ya citado (p. 182 ss.).

El más sensacional de los descubrimientos papirológicos relativos a nuestro poeta es el texto que ofrece el Papiro de Colonia (Pap. Colon. inv. 7511) publicado por Merkelbach y West en la revista Zeitschrift für Papyrusforschung und Epigraphik (14, 2, 1974, p. 97 ss.). Se trata de un texto epódico, bastante largo (31 versos, algunos muy estropeados) que contiene la descripción (o la narración) de una relación LII, $2^{\circ}-2$ 
amorosa entre un hombre y una mujer. La lengua, muy cargada de términos eróticos y sexuales, ha sido objeto de una buena cantidad de estudios, así como el resto de los aspectos que ofrece este curioso fragmento que, sin aportar nada nuevo sobre la poesía arquiloquea tal como la conocemos, ofrece aspectos de detalle curiosos. El fragmento ha sido últimamente muy estudiado (Degani, Marcovich, Th. Gelzer, van Sickle, Kamerbeek, Lasserre, Treu, Gentili, Cataudella, Gallavotti, Stössl, Melero, etc.).

Como hemos indicado ya que no se trata, aquí, de ofrecer un panorama detallado y pormenorizado de los estudios recientes sobre la lírica arcaica, sino de recoger algunas impresiones de lectura, pasaremos como sobre ascuas sobre algunas personalidades poéticas de la época. Señalaremos que sobre Safo, aparte algunos artículos sobre temas concretos o sobre alguno de sus poemas ( $\mathrm{y}$ aquí mencionaremos los trabajos de Privitera, Gentili, Lanata, Lasso de la Vega), merecen especial mención algunos libros importantes sobre esta poetisa: así el libro de D. Page, Sappho and Alcaeus, Cambridge 1959 (con inteligentes comentarios a los poemas más completos y una visión sintética de la poesía de los dos poetas lesbios); el libro de Fernández-Galiano, Safo (Madrid 1958), que contiene una amplísima información bibliográfica sobre aspectos muy variados (incluyendo aspectos del influjo de Safo en la posteridad), y el estudio de H. Saake (Zur Kunst Sapphos, Munich 1971) que, aparte ofrecer los principales poemas con la bibliografía relativa a las distintas interpretaciones y análisis de cada verso de cada uno de estos poemas, intenta una visión sintética del arte sáfico: su arte se caracterizaría, para este autor, por la homogeneidad de su temática: el tema dominante es la añoranza (Sehnsucht).

Estesícoro se ha visto favorecido, últimamente, por una serie de descubrimientos papirológicos que ha determinado, a su vez, una ola de trabajos re-analizando el sentido de su obra. Ahora sabemos, por ejemplo, que este poeta compuso no una, sino dos Palinodias, y a esta cuestión han vuelto estudiosos como C. M. Bowra ( $"$ The two Palinodes of Stesichorus», Classical Review, 1963, p. 1 ss.; Olivieri, "O problema das duas Palinodias de Estesicoro" (Humanitas, 1973/74, p. 265 ss.), Devereux ("Stesichoros' Palinodes», Rheinisches Museum, 1973, p. 206 ss.), López Eire («Estesícoro autor de Palinodias», Estudios clásicos). El papiro que nos ha proporcionado esa información (Pap. Ox. XXIX 33 36) ha sido editado por Page (Poetae melici Graeci, p. 106).

Ello ha llevado a un abordaje nuevo de la figura de este poeta: de un lado, trabajos concretos sobre obras concretas (como Robertson, 
Peek, de Hoz), otros que intentan una nueva síntesis (López Eire, Adrados, Calvo Martínez, West).

$\mathrm{Y}$ pasemos rápidamente a Píndaro, profundamente editado y estudiado en los últimos lustros. Por lo pronto, una constatación importante: coincidiendo con la corriente antibiográfica en los estudios literarios (un caso es la penetración del estructuralismo en la crítica), se ha superado completamente la actitud interpretativa de un Wilamowitz (Pindaros, Berlín 1922), para quien la poesía pindárica sólo tiene interés por los datos que pueda proporcionar para la reconstrucción del cursus biográfico del poeta. Apuntan, hoy, otras direcciones, algunas francamente interesantes. La superación definitiva del biografismo aparece claramente esbozada en el inconcluso trabajo de Bundy (Studia pindarica, Berkeley 1962) y su discípulo D. C. Young (quien, por otra parte, ha ofrecido un intereasnte esbozo de la historia de la crítica pindárica en su "Pindaric criticism», reproducido en el volumen colectivo editado por W. M. Calder III, Pindaros und Bacchylides, Darmstadt 1970, pp. 1-95; puede verse asimismo la puesta al día de la cuestión en J. S. Lasso de la Vega, Estudios clásicos 21, 1977, p. 59 ss.).

Acaso el libro más "heterodoxo" que sobre nuestro poeta se haya publicado en los últimos lustros sea el de Norwood (Pindar, Berkeley 1945), quien arremete duramente contra el excesivo filologismo con que se ha abordado a Píndaro, proponiendo, por su parte, una exégesis "simbolista». En el extremo opuesto tendríamos que citar a Thummer (en su edición y comentario-traducción de las 1stmicas, Heidelberg 1968), que pretende explicar en gran parte la poesía pindárica partiendo del análisis y reglas del género encomiástico. Sigue en este camino, en cierto modo, la línea trazada por W. Schadewaldt (Der Aufbau des pindarischen Epinikion (reimpresión Darmstadt 1966; la primera edición es de 1928), que, a su vez, depende de la exégesis de Boeckh.

$\mathrm{Si}$ intentamos una somera clasificación de los trabajos consagrados a Píndaro, podríamos establecer una serie de apartados:

a) Análisis de conjunto de su obra: así Bowra, Pindar, Oxford 1964 , que es un impresionante estudio donde se tocan todos los problemas.

b) Estudios encaminados a estudiar la primera época - la de formación artística- del poeta: aquí caben, junto al libro de Schwenn, Der junge Pindar, Berlín 1940, el interesante, aunque breve, estudio de M. Untersteiner, La formazione poetica di Pindaro, Florencia 1951. En cierto modo puede colocarse aquí el trabajo de P. A. Bernardini ( $«$ Linguaggio e programma poetico in Pindaro», Quaderni Urbinati, 1967, 
p. 80 ss.) que coincide con Untersteiner en el interés por la relación poesía-poética en nuestro autor.

c) Estudios que analizan la raíz aristocrática (dórica en el sentido de Defradas, Les thèmes de la propagande delphique, París 1954) de críticos como G. Méautis (Pindare le Dorien, Neuchâtel 1962) y Ed. Des Places (Pindare et Platon, París 1949).

d) El problema del mito y de su técnica poética, cuyo ejemplo más claro es el análisis de A. Koehnken, Die Funktion des Mythos bei Pindar, Berlín 1971 (al que hemos hecho ciertas objeciones en nuestra reseña en el Boletin del Inst. de Est. helénicos, 1973) y, sobre todo, H. Gundert, en un libro algo antiguo, pero muy iluminador (Pindar und sein Dichterberuf, Francfort 1935). Hay que añadir aquí el estudio de L. F. Guillén, Pindaro. Estructura y resortes del quehacer poético, Madrid 1975. En general, se ha estudiado, junto a otros poetas, la idea de su conciencia poética y profética: así en el trabajo de H. Maehler, Die Auffassung des Dichterberufs im frühen Griechentum bis zur Zeit Pindars, Gotinga 1963, y, para Píndaro en concreto, J. Duchemin, Pindare, poète et prophète, París 1955, cuya tesis central, Píndaro visto como un poeta órfico-pitagórico, me parece fallida.

e) El problema de la cronologia, por las implicaciones que tiene con respecto a la evolución artística del poeta, ha sido abordado en varias ocasiones y es un caballo de batalla de la crítica pindárica de hoy. Se han ocupado del problema, recientemente, $\mathrm{W}$. Theiler, el mismo Schadewaldt y Lloyd-Jones. Cf. un análisis detallado en St. Fogelmark, Studies in Pindar, Lund 1972, y Lasso de la Vega (art. antes citado).

f) La aplicación del método antibiográfico en la exégesis de Píndaro puede verse en dos trabajos concretos de Young: Pindar Isthmian 7: Myth and exempla (Leiden 1971), que quiere interpretar la Oda como el tratamiento literario de un topos, y Three Odes of Pindar (Leiden 1968), que ensaya el mismo método con la Pit. XI, la Pit. III y la Ol. VII.

g) La posición sociológico-política de Píndaro, un aristócrata que vive de espaldas al mundo contemporáneo, y la comparación de esa ideología con la de un poeta "progresista" puede verse en la obra, muy interesante, de J. H. Finley Jr., Pindar and Aeschylus, Cambridge, Mass., 1955.

h) Sobre el estilo, mencionaremos dos obras concretas: una, la tesis doctoral de J. Péron (Les images maritimes de Pindare, París 1974, que recoge una buena bibliografía sobre el estilo); y el opúsculo de W. Stockert, Klangfiguren und Wortresponsionen bei Pindar, Viena 1969, que aborda aspectos del nivel sonoro de la poesía pindárica. 


\section{El dRAMa ClÁsico}

La trilogía constituida por Tragedia, Comedia y Drama satírico sigue interesando a los estudiosos, como siempre. Quizá menos el drama satírico, pese a que hoy, tras el descubrimiento del importante fragmento de los Ichneutai de Sófocles, y algunos fragmentos de Esquilo -sobre todo los Dictiulkoi, "echadores de redes"- sabemos hoy más que hace unos lustros en qué consistía, realmente, la técnica y los procedimientos de este subgénero.

Por lo pronto, una constatación: por lo general, en el campo de los estudios clásicos, los problemas de origen se van dejando de lado, mientras apuntan otras orientaciones. La génesis de la poesía homérica, de la tragedia, de la comedia, de la obra tucididea, ha dado, en cantidad, muchas menos obras que otras cuestiones que hoy se consideran más candentes. Sin duda no es ajena a ese desplazamiento del centro de interés la paulatina penetración del estructuralismo en las ciencias de la cultura. En este sentido, podemos hablar de un cambio de rumbo en los estudios sobre el drama. Cierto que, en casos aislados, el tema del origen del drama es abordado a veces con criterios nuevos, como en el libro de F. R. Adrados (Fiesta, Comedia y Tragedia, Madrid 1972, que combina el método histórico con el estructural), o el breve estudio de G. E. Else (The Origin and early Form of Greek Tragedy, Cambridge, Mass., 1967, libro que propone atractivas hipótesis, aparte estudiar a fondo una figura tan borrosa hasta hace poco como Tespis). En la línea clásica, en cambio, se mueve el estudio de H. Patzer, Die Anfängen der gr. Tragödie, Wiesbaden 1962. Continúa siendo un libro básico el estudio de A. W. Pickard-Cambridge, Dithyramb, Tragedy and Comedy (reed. bajo el cuidado de Webster), Oxford 1962.

También interesa la investigación sobre el "sentido" de lo trágico, y los principios que determinan lo que cabría llamar una definición de la tragedia. Así, el importantísimo estudio de K. von Fritz "Tragische Schuld und poetische Gerechtigkeit in der gr. Tragödie" (incorporado, como capítulo primero, a su libro Antike und moderne Tragödie, Berlín 1962), que analiza históricamente el proceso que ha conducido a la creencia en una justicia poética dentro de la tragedia antigua. $O$ el estudio de A. C. Schlesinger, Boundaries of Dionysos, Cambridge, Mass., 1963, que intenta establecer los fundamentos áticos de una teoría de la tragedia.

Por lo que se refiere a estudios concretos sobre la tragedia, cabe mencionar el interés por el coro: libros como el de T. B. L. Webster 
(The Greek Chorus, Londres 1970), el del finlandés M. Kaimio (The Chorus of Greek Drama within the light of the Person and Number Used, Helsinki 1970), o el opúsculo de Jean Carrière (Le choeur secondaire dans le drame grec, París 1977) son una muestra bien patente, sin descontar los estudios de los coros en los distintos autores (así el trabajo de H. Parry, The choral odes of Euripides, tesis microfilmada de Berkeley 1963). En otro orden de cosas, hay que anotar los trabajos que se ocupan de aspectos como la esticomitia (W. Jens, Die Stichomythie in den frühen $g r$. Tragödien, Munich 1955), los cantos amebeos (cf. H. Popp, Amoibaion: zur Geschichte einer Dialogform der gr. Tragödie, Diss. Tubinga 1968), las rheseis (como el trabajo del danés H. F. Johansen, General Reflection in Tragic Rhesis: A Study of Form, Copenhague 1959).

Ya fuera de lo puramente técnico, estudios dedicados a aspectos de contenido, como el bello estudio de J. de Romilly (L'évolution du pathétique, París 1961), de M. Vílchez (El engaño en el teatro griego, Barcelona 1976) o el trabajo de J. de Hoz donde aborda aspectos del quehacer dramático (en EMERITA 46, 1978, p. 173 ss.).

Desearía detenerme, por razones distintas, en dos libros que creo importantes, si bien orientados en metodología y fines muy diversos. Por un lado, el estudio - ya algo antiguo- de G. Thomson (Eschilo ed Atene, trad. italiana, Turín 1949). Aparte que ofrece el interés de intentar un camino nuevo hacia la comprensión del origen de la tragedia -que habría salido de los ritos del clan primitivo, tesis muy discutible, pero atractiva - es que se trata de un libro que, pese al título, se ocupa de toda la evolución de la tragedia -en íntima relación con la sociedad- y enfocada desde un ángulo marxista. Menos ambicioso es el librito de J. de Romilly Time in Greek Tragedy (Ithaca, Nueva York, 1968). Se trata de analizar la visión del tiempo en los tres trágicos, y su función en la ideología de los poetas. Parte Romilly del principio según el cual "time shows through change» (p. 5) por lo que, en este sentido, la tragedia estaría íntimamente relacionada con el tiempo, pues lo esencial de ella es un proceso, un cambio que conduce de una situación feliz a otra desgraciada, por lo general. Analiza la diferencia esencial entre la visión del tiempo en la épica y en la tragedia. Frente al tempo del proceso épico - lento, sin prisas, como había señalado ya Goetheen la tragedia asistimos a un proceso lleno de intensidad y de concentración no sólo anímica, sino, sobre todo, temporal. Hay, por otra parte, profundas diferencias en la función del tiempo en cada uno de los trágicos: así, mientras en Esquilo predominan las conexiones distantes, la relación entre el presente y el pasado (éste gravitando decididamente 
sobre aquél), en Sófocles la acción es más compleja, con un fuerte predominio de la sorpresa dramática (cf., en este sentido, U. Parlavantza-Friedrich, Täuschungszenen in den Tragödien des Sophokles, Berlín 1969); en Eurípides, por el contrario, tras haber iniciado su ruta bajo la influencia de Sófocles, las crisis tienden a resolverse en incidentes varios e independientes.

$\mathrm{Y}$ pasemos a los distintos trágicos, comenzando por Esquilo. $\mathrm{He}$ dado una selección bibliográfica sobre este autor en mi edición - traducción de la Orestía (Barcelona 1979), lo que me evitará posibles repeticiones. Por su parte, K. von Fritz ha publicado en el libro antes mencionado (Antike und moderne Tragödie) algunos estudios suyos anteriores sobre aspectos de la obra de este trágico: la evolución de la leyenda de Orestes, el problema de la reconstrucción de la trilogía de las Danaides, y, sobre todo, ha llevado a cabo una puesta al día sobre la discusión en torno a la problemática figura de Eteocles en los Siete contra Tebas.

Como estudios de conjunto, señalaremos el reciente de 0 . Taplin, The Stagecraft of Aeschylus, Oxford 1977 (centrado, empero, de un modo especial sobre aspectos de la técnica dramática). El libro de J. de Hoz (On Aeschylean Composition, Salamanca 1979) es un importante esfuerzo por ofrecer un análisis estructural de la tragedia esquílea. Sólo ha aparecido, por ahora, la primera parte de la obra. Orientado hacia una interpretación política (que ha estado en boga en los últimos años) mencionaremos el trabajo de C. Miralles, Tragedia $y$ Politica en Esquilo, Barcelona 1968 (que recoge la bibliografía sobre esta dimensión de la obra esquílea).

El estudio de alguna obra en concreto (A. F. Garvie, Aeschylus' Supplices Play and Trilogy, Cambridge 1969; G. Grossmann, Promethie und Orestie, Heidelberg 1970; R. Unterberger, Der gefesselte Prometheus des Aischylos, Berlín 1968) o de alguna de sus figuras (H. J. Dirksen, Die aischyleische Gestalt des Orest, Nuremberg 1965) puede cerrar este apartado sobre Esquilo, no sin mencionar el volumen colectivo (editado por H. Hommel) Wege zu Aischylos (Darmstadt 1974, dos tomos).

Buena brújula para orientarse en los focos de interés que despierta, hoy, Sófocles, puede ser el volumen, editado por H. Diller, Sophokles (Darmstadt 1967). Siguen apareciendo estudios de conjunto sobre este trágico, de orientación muy diversa: así, A. J. A. Waldock ha enfocado a Sófocles como buen conocedor de la trama dramática (Sophocles the Dramatist, Cambridge 1966, 1951 1 ); G. M. Kirkwood (A Study of Sophoclean Drama, Ithaca, N. Y., 1958) realiza un estudio general sobre 
el teatro de nuestro trágico; y lo mismo hacen G. Ronnet (Sophocle, poète tragique, París 1965), Winnington-Ingram (Sophocles. An Interpretation, Cambridge 1980) y Ch. Segal (Tragedy and Civilisation. An Interpretation of Sophocles, Cambridge, Mass., 1981). B. M. W. Knox (The Heroic Temper, Berkeley 1966) hace un análisis de la contextura psíquica y moral de los personajes de Sófocles. Muy discutible es la visión que nos da $\mathrm{H}$. Musurillo (The Light and the Darkness, Leiden 1967), que termina su trabajo intentando un esbozo de la "filosofía" de nuestro autor y con unos versos de Calderón («el delito mayor / del hombre es haber nacidon).

Pero, posiblemente, el trágico más estudiado y analizado ha sido, en los últimos lustros, Eurípides: desde estudios de conjunto, algunos ya algo antiguos, como los de Rivier (Essai sur le tragique d'Euripide, Lausana 1944, a mi juicio uno de los más lúcidos trabajos para descubrir el poeta que hay en Eurípides) o Conacher (Euripidean Drama, Toronto 1967), pasando por un par de libros que intentan estudiar la obra euripidea como reflejo de las condiciones históricas de la Atenas de su tiempo (Ed. Delebecque, Euripide et la guerre du Peloponnèse, París 1951; R. Goossens, Euripide et Athènes, Bruselas 1962), o el intento de ver reflejada en su obra las condiciones sociales de la época (V. di Benedetto, Euripide: teatro e società, Turín 1971), la figura del último trágico ha sido objeto de inconstantes profundizaciones. Un buen indicio de las orientaciones modernas sobre este autor puede ser el volumen de la Fundación Hardt (VI, Euripide, Ginebra 1960) o el volumen preparado por E.-R. Schwinge (Euripides, Darmstadt 1968). Una introducción general, intentando poner al día la discusión contemporánea sobre el poeta, he dado en mi libro Euripides. Tragedias (Barcelona 1981).

Párrafo aparte merece el trabajo de $\mathrm{H}$. Rohdich, Die euripideische Tragödie. Untersuchungen zu ihrer Tragik, Heidelberg 1968: como es sabido, a finales del siglo pasado dominó la tendencia a ver en Eurípides un "pensador" racionalista, propagador de la ideología sofística. El libro más característico de esa tendencia (aparte el ya clásico de W. Nestle, Euripides der Dichter der gr. Aufklärung, Stuttgart 1901) es el de Verrall (Euripides the Rationalist, Londres 19052). Naturalmente, la visión nietzscheana del poeta ha gravitado profundamente sobre los críticos que han enfocado a Eurípides bajo esa perspectiva. Pero Rohdich adopta una actitud completamente opuesta: la tesis sostenida a lo largo del libro es, precisamente, la contraria: identifica el movimiento socrático y sofístico (en parte es un punto de vista que puede aceptarse), y presenta a nuestro trágico como una reacción contra la 
ideología representada por la mencionada corriente ideológica, con su optimismo ético y su intelectualismo (cf. los detalles de este libro en mi reseña, EMERITA 38, 1970, p. 271 ss.).

En un apartado concreto cabe colocar aquellos trabajos que, si bien no se proponen un estudio completo de la obra, sí abordan aspectos bastante amplios de su obra o de su pensamiento y su técnica: por un lado, los esfuerzos por establecer una cronologia relativa de la obra euripidea, labor donde, como se sabe, no hay acuerdo completo entre los críticos. M. Fernández-Galiano ha llevado a cabo un serio intento por hacer una puesta al día del problema, apuntando sus propios puntos de vista («Estado actual de los problemas de cronología euripidea», Estudios clásicos 11, 1967, p. 321 ss.); por otro, estudios sobre grupos de obras más o menos relacionadas entre sí por la temática o por la técnica empleada: así, las obras referentes al ciclo troyano han sido abordadas, primero, por F. Jouan, Euripide et la légende des chants cypriens, París 1966, y luego, en un estudio más amplio del tema, por R. Scodel, The Troian Trilogy of Euripides, Gotinga 1980. O los trabajos de un A. Garzya (Pensiero e tecnica dramatica in Euripide, Nápoles 1962), cuyo título no es muy indicativo del tema tocado, que es buscar la "nota esencial del drama de Eurípides»; se estudia en este trabajo el tema del "salvador" (como Heracles en Alcestis, por ejemplo) en todas sus múltiples y variadas formas. En otro orden de cosas, pero enfocado bajo el prisma de un análisis global, o casi, de la obra del trágico, abordando aspectos técnicos, la tesis de N. C. Hourmouziades, Production and Imagination in Euripides, Atenas 1965 (que estudia la forma y la función del espacio escénico). Son asimismo significativos una serie de estudios enfocados hacia la comprensión del sentido del mito en nuestro autor, como el del crítico americano C. H. Whitman (Euripides and the full Circle of Myth, Cambridge, Mass., 1974), que quiere ser una especie de manifiesto contra el "verrallismo" aún existente en nuestro siglo (así el trabajo de Greenwood, Aspects of Euripidean Tragedy, Cambridge 1953) proponiendo, como tesis, que el mito no es parodia en su tragedia. Finalmente colocaremos bajo ese apartado trabajos como el de E. Valgiglio, Il tema de la morte in Euripide, Turín 1966, que intenta un balance, quizá demasiado matemático, entre los pasajes que presentan la vida como un bien o como un mal (en ese mismo contexto, pero enfocado bajo un prisma estrictamente filológico, el estudio de M. McDonald, Terms for Happiness in Euripides, Gotinga 1978, puede aportar datos para un estudio del campo semántico de la felicidad y la desgracia en nuestro trágico). 
La serie de estudios dedicados a obras concretas (o a un pequeño grupo) es bastante abundante. Reseñaremos sólo las que creemos más significativas. Podemos abrir la lista con el curioso intento de reivindicar el valor literario de algunas piezas que la crítica, por lo general, ha condenado por ser exclusivamente piezas de circunstancias, como Las Suplicantes y Los Heraclidas (G. Zuntz, The political Plays of Euripides, Manchester 1955), o los amplios estudios de K. von Fritz sobre Alcestis y Medea (Antike und moderne Tragödie, p. 256 ss.), el análisis de Ritchie sobre el Reso, cuya autenticidad y fecha relativamente reciente sostiene el autor (The Authenticity of the Rhesus of Euripides, Cambridge 1964). Asimismo los estudios de G. Paduano (La formazione del mondo ideologico e poetico di Euripide, Pisa 1968), que analiza las dos primeras obras conservadas; el de W. Fauth (Hippolytos und Phaidra, Wiesbaden 1959), el de M. Imhof (Euripides' Ion, Munich 1966) $\mathrm{y}$ el de G. Mellert-Hoffmann (Untersuchungen $z u$ "Iphigenie in Aulis" des Euripides, Heidelberg 1968). Lugar de honor merece el breve, pero enjundioso estudio de Winnington-Ingram sobre las Bacantes (Euripides and Dionysos, Cambridge 1948, reeditado en Amsterdam en 1969).

Respecto al estilo y fenómenos emparentados como la técnica del verso, remitimos a dos de los estudios más sobresalientes: S. A. Barlow (The imagery of Euripides, Londres 1971) y E. R. Schwinge (Die Verwendung der Stichomythic in den Dramen des Euripides, Heidelberg 1968).

Curioso, por el enfoque del trabajo (intenta ofrecer la tragedia euripidea como una posible luz para el hombre moderno), hay que citar el trabajo de Ph. Vellacott, Ironic Drama. A Study of Euripides' Method and Meaning (Cambridge 1975).

La bibliografía básica sobre la Comedia hasta 1950 puede verse cómodamente en Fifty Years of Classical Scholarship (editado por Platnauer), Oxford 1954 (hay una reed. de 1968, puesta al día). Acúdase, asimismo, a la reseña crítica sobre Aristófanes en Lustrum (2, 1957, pp. 52-112), a Komornicka ("Aristofane negli ultimi decenni», Cultura e Scuola 23, 1967, p. 37 ss.), y al artículo del Pauly-Wissowa (s. v. Komödie). Para Aristófanes, en concreto, Th. Gelzer (art. Aristophanes der Komiker, RE de Pauly-Wissowa, Suppl. XII, 1970, col. 1393 s. De entre los cómicos de la Comedia antigua, aparte Aristófanes, más estudiados, está Cratino. La tesis doctoral de J. Th. M. F. Pieters (Cratinus. Bijdrage tot de geschiedenis der vroegattische comedie, Leiden 1946) puede ser considerada el punto de arranque de una serie de estudios relativos a los rivales de Aristófanes. Este estudio supera, con mucho, el art. de Körte sobre Cratino ( $R E$ de Pauly-Wissowa, XI 2, 1922, col. 1647 ss.). 
Una buena puesta al día de lo que se sabe sobre este importante cómico puede verse en E. Vintró "Cratino: comedia y política en el siglo V» (Bol. del Instituto de Est. Hel. 9, 1975, p. 45 ss.). Y este título nos lleva al tema de la crítica y el ataque político, que suele ser básico en la Comedia antigua. Por lo que atañe a Pericles - tan atacado, sobre todo por Cratino- cf., últimamente, J. Schwarze, Die Beurteilung des Perikles durch die attische Komödie, Munich 1971 (y mi reseña crítica en Bol. Inst. Est. Hel. 6, 1, 1972, p. 141 ss.), que consagra las pp. 5-90 a Cratino. Los intentos de reconstruir algunas piezas del comediógrafo (sobre todo el Dionisalejandro) tal como los realiza Schwarze me parecen poco logrados (cf. mi reseña antes citada); pero, en conjunto, este estudio es importante para valorar, en un caso concreto, el papel crítico de la Comedia.

Tras la obra clásica de G. Murray (Aristophanes, Oxford 1933), han ido apareciendo interesantes estudios de conjunto, o sobre temas concretos, acerca de este autor. Mencionemos a F. Ballotto (Saggio su Aristofane, Florencia 1963), C. F. Russo (Aristofane autore di Teatro, Florencia 1962), Whitman (Aristophanes and the comic Hero, Cambridge, Mass., 1964), K. J. Dover (Aristophanic Comedy, Londres 1972) y J. S. Lasso de la Vega ( Realidad, idealidad y política en la comedia de Aristófanes», en De Safo a Platón, Barcelona 1976, p. 243 ss.). Los aspectos sociológicos de la comedia aristofánica fueron abordados en su dia por V. Ehrenberg (The People of Aristophanes, Nueva York $1972_{2}, 1943_{1}$ ).

Los aspectos técnicos del teatro aristofánico han sido estudiados desde distintos ángulos de interés: P. Händel (Formen und Darstellungsweisen in der aristophanischen Komödic, Heidelberg 1963) ha llevado a cabo un intento por estudiar la técnica del autor poniendo de relieve lo que él llama su originalidad respecto a sus precursores; Th. Gelzer, aparte un interesante estudio sobre "Tradition und Neuschöpfung in der Dram. des Aristophanes» (Antike und Abendland 8, 1959, pp. 15-31), es autor de un amplio trabajo (Der epirrhematische Agon bei Aristophanes, Munich 1960) donde, empleando la terminología del venerable Zielinski, analiza este elemento tan característico de la comedia aristofánica.

Pero es sobre todo el estudio de los elementos de la comicidad de Aristófanes por donde ha discurrido, sobre todo, la investigación. Y aquí hay que mencionar los estudios de W. Horn (Gebet und Gebetsparodie in den Komödien des Aristophanes, . Nuremberg 1972), Sifakis (Parabasis and Animal Chorus, Londres 1971), Rau (Paratragodia. Untersuchungen einer komischen Form bei Aristophanes, Munich 1967), sin olvidar los 
elementos de su estilo, tanto en sí como en lo que en él contribuye a la comicidad (estudios de K. J. Dover, Quad. Urb. 9, 1970, p. 7 ss.; E. W. Hope, The language of Parody, 1906, ya anticuado; A. M. Komornicka, Métaphores, personifications et comparaisons dans l'oeuvre d'Aristophane, Wrocław 1964, o la obra de conjunto de Taillardat, Les images d'Aristophane. Etudes de langue et de style (París 1965).

\section{La Historiografía CLÁSICA}

Tras las reacciones que, a partir de la primera guerra mundial, se producen en todos los campos de la Filología clásica, asistimos a una constante reivindicación de Heródoto como historiador, calificativo que la hipercrítica alemana le negó en determinados momentos. He dado la bibliografía más importante hasta 1960 en mi trabajo (en colaboración con J. Vaqué) "Ensayo de una bibliografía crítica de Heródoto» (Estudios clásicos 6, 1961, pp. 99-127). Puede asimismo ser útil la bibliografía selectiva que recoge W. Marg en el volumen colectivo Herodot. Eine Auswahl der neueren Forschung, Darmstadt 1965. Para el lector español, el trabajo de J. S. Lasso de la Vega "La objetividad del historiador en Heródoto" (en el libro De Safo a Platón, Barcelona 1976, p. 171 ss.) puede serle de mucha utilidad. En 1932 aparece el volumen de introducción de la edición-traducción de Heródoto en la Col. Budé (obra de Ph.-E. Legrand). En 1937 Pohlenz publica su intento de reivindicación decidida del autor en un libro cuyo título es bien explícito: Herodot, der erste Geschichtsschreiber des Abendlandes (Leipzig, Teubner). El interés por el historiador de las guerras médicas -entre otras cosas- va, pues, en aumento. Se estudian aspectos concretos: Regenbogen hace una inteligente excursión por su obra ( «Herodot und sein Werk", en Die Antike 6, 1930, p. 202 ss.); W. Aly aborda los aspectos populares y novelístico-folklóricos contenidos en el historiador (Volksmärchen, Sage und Novelle bei Herodot und seine Zeitgenossen, Gotinga 1921); Reinhardt se ocupa de su visión de las guerras contra Persia (uno de los puntos más importantes de su obra) en su trabajo "Herodots Persergeschichte», aparecido en 1940 y reproducido más tarde en su obra Vermächtnis der Antike (Gotinga 1960, p. 133 ss.); F. Jacoby ofrece, en artículo magistral (publicado un año antes de la primera guerra europea) del Pauly-Wissowa (Suppl. II) una visión sobre la génesis de su obra, tema que abordará más tarde G. de Sanctis ( LLa composizione della storia di Erodoto", aparecido en la Riv. di Fil. class. de 1926 e incorporado a su libro Studi di Storia della storiografia greca, 
Florencia 1951, p. 21 ss.). Y así, paulatinamente, a partir de 1945, una vez terminada la guerra mundial, el estudio del primer historiador de occidente va en aumento: se analiza su estilo (Denniston, van Groningen, van Otterlo, entre otros), se discuten los pasajes más importantes de su obra, como la introducción (Erbse, "Der erste Satz im Werke Herodots", en Festschrift Snell, Munich 1956, p. 209 ss.), o el sentido del último capítulo (cf. H. Bischoff, Der Warner bei Herodot, BornaLeipzig 1932, p. 78 ss.), la forma y contenido de la obra (Immerwahr, "Ergon. History as a Monument in Herodotus and Thukydides", Amer. Journ. of Philology 81, 1960, p. 251 ss.), los oráculos, tan frecuentes y significativos en su obra ( $\mathrm{R}$. Crahay, La littérature oraculaire chez $\mathrm{He}$ rodote, París 1956; J. Kirschberg, Die Funktion der Orakel bei Herodot, Gotinga 1965), la experiencia de la guerra contra Persia (Hignett, Xerxes' Invasion of Greece, Oxford 1963; W. Kierdorf, Erlebnis und Darstellung der Perserkriege, Gotinga 1966), su técnica narrativa (J. Cobet, Herodots Exkurse und die Frage der Einheit seines Werkes, Wiesbaden 1971; I. Beck, Die Ringkomposition bei Herodot, Hildesheim 1971; H. Montgomery, Gedanke und Tat, Lund 1965), sus ideas políticas, religiosas y afines (Fr. Egermann, "Arete und tragische Bewussheit bei Sophokles und Herodot", en el volumen Vom Menschen in der Antike, Munich 1957; A. Heubeck, Das Nationalbewusstsein des Herodot, Diss. Erlangen 1936; H. Kleinknecht, "Herodot und Athen", en Hermes 75, 1940, p. 241 ss.; Pippidi, "Sur la philosophic de l'histoire d'Hérodote", en Eirene 1, 1960 , p. 75 ss.), la posición de nuestro historiador dentro de la historiografía griega o universal (A. Momigliano, "The Place of Herodotus in the History of Historiography", en Secondo contributo alla storia degli studi classici, Roma 1960, p. 29 ss.), los datos que aporta sobre los diversos paises de que habla, en especial de Egipto (aparte el viejo libro de A. Wiedemann, Herodots zweites Buch, Leipzig 1892 [reed. 1971], el trabajo de J. A. Wilson, Herodot in Egypt, Londres 1970), su personalidad (St. Flory, Arion 8, 1969, p. 99 ss.), su visión de la historia (Pagel, Die Bedeutung des aitiologischen Momentes für Herodots Geschichtsschreibung, Leipzig 1927; Gomme, The Greek attitude to poetry and history, Berkeley 1954, p. 73 ss.; Schadewaldt, "Das ReligiösHumane als Grundlage des geschichtlichen Objektivität bei Herodot", en Festschrift Rothfelds, Gotinga 1962; H. Verdin, De historisch-kritische methode van Herodotus, Bruselas 1971).

Todo ello $-\mathrm{y}$ mucho más que no podemos citar por falta de espacio- sin perjuicio de que aparezcan libros de conjunto sobre su obra y su persona (J. L. Myres, Herodotus, the father of History, Oxford 1953; A. de Selincourt, The World of Herodotus, Londres 1962). 
Vamos a ocuparnos ahora en concreto de algunos trabajos que, sin representar una aportación especial, han merecido, por diversas circunstancias, la atención del autor de estas líneas. Cronológicamente, el primero que nos interesa es el estudio, en polaco, de J. Wikarjak, Historia powszechna Herodota ( La Historia general de Heródoto»), Poznan 1961. El autor había ya publicado anteriormente a este trabajo algunos estudios consagrados al historiador; en éste intenta una visión sintética y, especialmente, la exposición de los motivos que indujeron a Heródoto a escribir su obra. La tesis defendida a lo largo del libro resulta, al punto luminosa y muchos puntos obscuros quedan aclarados si se tiene en cuenta que, si bien el interés geográfico no falta en las Historias, es lo histórico lo que de verdad ocupa el centro de la obra. El historiador quiere ocuparse de las más variadas manifestaciones culturales, artísticas, folklóricas y literarias. Sistemáticamente, luego, se va ocupando del problema, tan debatido, de si la obra está o no concluida, del método del historiador en la selección de su material, la etiología histórica tal y como la concibe Heródoto, las digresiones, que, según Wikarjak, no siempre, como suele creerse, son auténticos excursus (cf. en este sentido el trabajo de Cobet Herodots Exkurse und die Frage der Einheit seines Werkes citado, que sostiene la unidad de la obra siempre que no se pierda de vista que la historiê jónica, y con ella Heródoto, presenta una doble vertiente: "Herodot scheint -escribe el autor, p. 185- eine eigentümliche Zwischenstellung einzunehmen zwischen Dichtung und Geschichtsschreibung").

A decir verdad, a la hora de juzgar la coherencia de la tesis defendida por Wikarjak, las objeciones se acumulan: no resulta del todo claro, por ejemplo, por qué, después de todo, los primeros cinco libros están cargados de historiê - geografía, folklore, etnología- mientras los últimos tienen una definida orientación histórico-política. A juicio nuestro, se ha producido en el ánimo de Heródoto un innegable desplazamiento del interés. También me parece fallida la defensa que hace Wikarjak de muchos pasajes herodoteos considerados generalmente como digresiones, y que él se niega a ver como tales. El trabajo de van Otterlo sobre la Ringkomposition, no utilizado por el autor, habría podido ayudarle mucho: así, es curioso constatar que, precisamente, en las "digresiones» es donde son empleados con mayor frecuencia los procedimientos de la Ringkomposition (o composición en anillo), como ha señalado el citado crítico holandés. Y ese recurso es típico de las digresiones.

Dentro de los procedimientos de narración herodoteos se halla el que Theobald Spath llama doble enfoque (Das Motiv der doppelten 
Beleuchtung bei Herodot, Viena 1968): el recurso es bien conocido. Desde hace tiempo han constatado los intérpretes de Heródoto que este autor suele enfocar a sus personajes desde dos ángulos distintos de observación, sin preocuparse de armonizar la incongruencia, al menos aparente, que esa dualidad de enfoques produce. Puede uno preguntarse si se trata de meras contradicciones, y así es como, por lo general, se ha intentado resolver el problema. Pero las razones deben ser más profundas, y por ello se ha ido renunciando, por parte de los críticos, a esa simple explicación. Los filólogos han ensayado cada uno por su lado distintas respuestas: W. Schmid (Geschichte der gr. Literatur, I 2, p. 651) cree explicarlo acudiendo al deseo del historiador de dejar constancia de las distintas versiones por él conocidas; pero el mismo Heródoto en varias ocasiones afirma conocer otras versiones, pero sin especificarlas. I. Bruns (Das literarische Porträt der Griechen, p. 81), en pleno auge del positivismo y de la Quellenforschung, quería ver en este hecho el uso de fuentes diversas. Forderer sostuvo que Heródoto quería presentar los dos aspectos, la luz y la sombra, de sus personajes. W. Theiler cree hallar aquí una raíz heraclitea (la armonía a partir de elementos discordantes). Spath realiza un loable intento por explicar el fenómeno, aunque no ha tenido, a juicio nuestro, un éxito rotundo. El autor de este trabajo se niega a ver en el principio

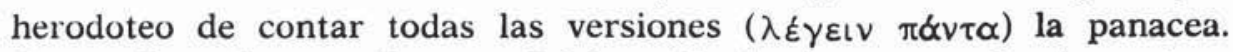
Contra Strassburger, Gomme, Pohlenz, Heubeck y otros, Spath sostiene que el principio antes mencionado excluye que el historiador no tenga sus propias filias y fobias, simpatías y antipatías. Tampoco acepta, de un modo absoluto, que el uso de fuentes distintas sea la causa de esa doble iluminación de sus personajes. Seguramente el reproche más grave que puede hacerse a Spath es que no ofrece una aclaración definitiva y contundente de los hechos. Se ofrecen varias razones, se rechazan otras. Pero el autor no realiza un análisis a fondo de tales razones. $\mathrm{Y}$ ello es lástima, porque hay momentos en que está a punto de dar con la solución que a nosotros nos parece la más acertada. Y es que Heródoto, que utiliza, como se sabe, muchas técnicas narrativas propias de la época arcaica, ha sabido emplear la que Heubeck ha llamado con razón "técnica del complemento", que consiste en que un mismo hecho es contado por personas distintas, cada una de las cuales ofrece una parte de la perspectiva, que, naturalmente, en cada caso es parcial, pero que consideradas todas permiten una visión más objetiva de los hechos. Es el método que emplea Homero, sobre todo en la Odisea, y que ha estudiado Heubeck (Der Odyssee-Dichter und die Ilias, Erlangen 1954) 
y que yo mismo he aplicado al análisis de la figura de Clitemestra en los poemas homéricos (EMERITA 27, 1959, p. 297 ss.).

Hay otro punto importante a considerar a la hora de llevar a cabo un estudio de la indicación de las fuentes que el propio Heródoto ha empleado: el historiador, como es bien sabido, cita fuentes en cuya existencia no es fácil creer. Y, por otra parte, tampoco es infrecuente en nuestro autor que diga haber oído, en sitios muy distantes entre sí, relatos que se complementan o se apoyan mutuamente sin que pueda hallarse explicación racional de esta relación entre ciudades y regiones tan alejadas.

El hecho ha sido abordado en varias ocasiones por los críticos de Heródoto. Ya en el siglo xIX Sayce y Panofsky intentaron hallar una solución al problema. Este último dedicó al tema la importante monografía, que constituyó su tesis doctoral, titulada Quaestiones de historiae herodoteae fontibus. Pars prima, Berlín 1885, cuya tesis central es que los datos que aportan las fuentes de Heródoto no tienen nada que ver con la realidad, y que éste las habría escogido porque se adaptaban al contenido de su narración. Para Panofsky las fuentes reales del historiador eran fuentes escritas. El trabajo de Panofsky ha sido sometido a fuertes críticas, sobre todo por parte de Jacoby; pero no se aportaba, a cambio, una explicación suficiente de la cuestión. Detlev Fehling lo ha intentado (Die Quellenangaben bei Herodot. Studien zur Erzählkunst Herodots, Berlín 1971). El estudio intenta, de entrada, hacer un planteamiento completo del problema de las "fuentes" herodoteas, aunque las conclusiones del libro en concreto trascienden el simple problema de las fuentes para ir a parar a problemas estilísticos y técnicos. Ya en el primer capítulo, analizando algunas de las narraciones del historiador (el tema de Helena y Proteo, narraciones sobre los Escitas, entre otras), son simplemente inventadas, sin que por ello haya que llamar a Heródoto un "falsificador": Heródoto sigue los principios del género, que, naturalmente, no es todavía historia en el sentido moderno del término. El capítulo segundo se propone establecer los principios en que se basa la "invención de las fuentes". Muchas de las categorías empleadas por el autor proceden de Panofsky, en especial el principio de la "fuente inmediata" ("Prinzip der nächstliegende Quellenangabe»). La conclusión del autor es que, en Heródoto, tenemos una enorme "ficción". Los escasos hechos conocidos por el historiador son elaborados mediante el procedimiento de la invención. Estamos, pues, en presencia de una, al menos aparente, vuelta a los principios hermenéuticos del siglo XIX, de acuerdo con los cuales Heródoto no merece, aún, el calificativo de historiador. La tesis no es nueva (ya Howald 
había sostenido doctrinas parecidas), y Fehling quiere justificarla adoptando una posición que pretende ser "histórica»: el problema (cf. p. 174) no debe plantearse en el sentido de Jacoby o von Fritz; no se trata de que haya en Heródoto una evolución espiritual que lo hace pasar de logógrafo a historiador: Heródoto quería narrar la guerra y los sucesos que la precedieron al estilo homérico, no al tucidídeo. Su vocación es la del narrador, no la del historiador.

Tucídides ha interesado mucho a lo largo de los últimos lustros, pero el interés por el historiador de la guerra del Peloponeso ha discurrido por otros derroteros distintos de los que siguieron los investigadores de la primera mitad del siglo $\mathrm{xx}$. Puede verse una selección bibliográfica de los estudios sobre el historiador, en el siglo $\mathrm{xx}$, en mi reciente libro Tucídides. Historia, ética y politica, Madrid 1981, p. 349 ss.

De entre los libros de carácter general aparecidos últimamente, hay que destacar el trabajo de Luschnat Thukydides der Historiker (Stuttgart 1971), que no es sino la tirada aparte del artículo sobre el historiador en el Pauly-Wissowa (Suppl. XII), que recoge todo lo más importante que hay que saber del autor. Asimismo, el libro antes mencionado del autor de estas líneas. Una buena selección de los artículos más importantes de los más notables estudiosos de Tucídides (Regenbogen, Pohlenz, Patzer, E. Bayer, H. Gundert, H. Erbse, Wassermann, H. Strassburger, Romilly, Westlake, Diller, Lendle) se contiene en el volumen XCVIII de la colección alemana "Wege der Forschung», editado con el título de Thukydides por H. Herter.

La llamada "cuestión tucidídea" ha recibido prácticamente un carpetazo final: tras los intentos de W. Schadewaldt (Die Geschichtsschreibung des Thukydides, Berlín 1929) y algunas contribuciones menores sobre el tema, A. Grosskinski (Das Programm des Thukydides, Berlín 1937) emitió lo que por el momento puede considerarse la conclusión más aceptable: el historiador redactó el conjunto de su obra tras el 404.

En cambio hay otros aspectos que preocupan a la investigación: de un lado, la guerra por él narrada y el problema de las causas que la motivaron: aquí hay que mencionar los estudios de D. Kagan, The Outbreak of the Peloponnesian War (Londres 1969), que discute la tesis de Tucídides según la cual en 431 las condiciones para una guerra eran adecuadas (el autor cree que había más "razones» para ir al enfrentamiento Atenas-Esparta en 445), y el libro que es la continuación de éste (The Archidamian War, Londres 1974).

El carácter "trágico" de su obra ha sido puesto de relieve por H. P. Stahl (Thukydides. Die Stellung des Menschen im geschichtlichen Pro-

LII, $2 .^{\circ}-3$ 
zess, Munich 1966) y el artículo de F. W. Walbank («History and Tragedy", en Historia 9, 1960, p. 216 ss.). Sobre las causas de la guerra, además, G. E. M. de Ste. Croix (The origins of the Peloponnesian War, Londres 1972).

Como historiador ha sido asimismo enfocado en varias ocasiones: de un lado, se ha realizado un esfuerzo considerable por ofrecer una visión sinóptica de su narrativa (F. E. Adcock, Thucydides and his History, Cambridge 1963); de otro, se ha profundizado en lo que cabe llamar sus "métodos": así el luminoso trabajo de J. de Romilly (Histoire et raison chez Thucydide, París 1956), o el más atrevido de V. Hunter, Thucydides, the artful reporter, Toronto 1973. Es importante el estudio de L. Edmunds, Chance and Intelligence in Thucydides (Cambridge, Mass., 1975), que analiza la oposición gnôme-tyche en la obra del historiador, desarrollando, así, aspectos tocados por Hunter y Stahl.

Pero el problema más preocupante ha sido el de su "objetividad». Hoy tiende a imponerse la tesis (Hunter, Stahl, Romilly, Woodhead ["Thucydides' Portrait of Cleon», en Mnemosyne, 1960, p. 289 ss.]) de que, sin dejar de ser un autor "objetivo", el historiador tiene sus fobias y sus filias (Cleón es una de sus fobias; Pericles, la más notable filia: sobre Pericles y Tucídides es importante el estudio de E. Bayer, "Thukydides und Perikles", en Würzburger Jahrbücher 3, 1948, p. 1 ss.). En relación con ese problema está el de su ideología política: una serie de estudios han puesto de relieve que Tucídides no es el panegirista de la democracia ateniense, sino un oligarca que ha sido ganado por la política periclea. Así, de un lado, H. Flashar, Der Epitaphios des Perikles. Seine Funktion im Geschichtswerk des Thukydides (Heidelberg 1969), intenta demostrar, creemos que equivocadamente, que el discurso funerario del libro II no es, como tiende a creerse, un panegírico de la democracia ateniense, sino todo lo contrario (el discurso ha sido analizado al pormenor por Th. Kakridis, Der thukydideische Epitaphios, Munich 1961, desde el punto de vista estilístico). Sobre los discursos en concreto, hay que ver el volumen colectivo, editado por Stadter, The Speeches of Thucydides (Chapel Hill 1973).

En relación con el problema antes aludido, hay que mencionar la polémica que se desató, hacia los años cincuenta, sobre si el imperio ateniense fue o no popular, y si Tucídides ha reflejado el clima auténtico de los súbditos de Atenas: así, inició el tema Ste. Croix ("The character of the Athenian Empire», Historia 3, 1954, p. 1 s.), quien sostuvo que, aun utilizando los datos del historiador, puede deducirse que el imperio no era popular en la Grecia del siglo v. Le contestó Bradeen (Historia 
9, 1960, p. 257 ss.) y prosiguió la polémica T. J. Quinn (Historia 13, 1964, p. 257 s.).

En relación con su discutida o aceptada neutralidad está el tratamiento de los políticos por parte de Tucídides. Un buen análisis en H. D. Westlake, Individuals in Thucydides, Cambridge 1968. Por lo que respecta a las motivaciones de la conducta de sus personajes, sobre todo los políticos, Ch. Schneider (Information und Absicht bei Thuky. dides, Gotinga 1974) ha realizado un estudio pormenorizado.

Unas notas dispersas antes de cerrar este capítulo: por lo que respecta a la estructura de la obra, el libro más reciente de $\mathrm{H}$. R. Rawlings III (The Structure of Thucydidean History, Princeton 1981) establece la "estructura trágica" en la obra (como, por otra parte, han hecho otros críticos, por ejemplo, Kitto, en el capítulo dedicado a nuestro autor en su libro Poiesis. Structure and Thought, Berkeley 1966).

El estilo ha ocupado menos a los críticos: el léxico ha sido abordado por P. Huart, Le vocabulaire de l'analyse psychologique dans l'oeuvre de Thucydide, París 1968, libro muy rico de contenido y que trasciende el simple estudio del vocabulario para plantear aspectos del modo de pensar del historiador. Ha abordado la relación existente entre estilo y pensamiento en nuestro autor G. Wille ( $" \mathrm{Zu}$ Stil und Methode des Thukydides", en Synusia. Festgabe für W. Schadewaldt, Pfullingen 1965, p. 53 ss.). Buenas ideas sobre los orígenes del estilo del historiador en J. H. Finley Jr., Three Essays on Thucydides (Cambridge, Mass., 1967, p. 55 ss.), que estudia los arcaísmos de su estilo y enfoca el problema de la unidad de su estilo y, a través de él, de su obra.

El problema del imperialismo y el poder ha sido, asimismo, abordado en varias ocasiones. Ya nos hemos referido a la cuestión de la popularidad del imperio ateniense. Sobre las ideas de Tucídides en torno al poder y al imperio hay que citar dos obras importantes: Romilly (Thucydide et l'impérialisme athénien, París 1948, que está aún enfocada desde la perspectiva de la cuestión tucidídea) y R. Meiggs, The Athenian Empire, Oxford 1972.

Respecto a las posibles relaciones entre la medicina hipocrática y nuestro historiador, merece citarse (tras el estudio positivo de Kl. Weidauer, Thukydides und die Hippokratische Schriften, Heidelberg 1954, que cree en una profunda influencia del método de los médicos en los del historiador) a Ch. Lichtenhaeler (Thucydide et Hippocrate vus par un historien de la médecine, Ginebra 1965), que ha hablado simplemente de espíritus gemelos, descartando un influjo directo. La cosa es más que discutible. Es valioso, en cambio, el capítulo que dedica a 
la descripción de la peste de Atenas, capítulo donde recoge el autor la bibliografía más importante sobre el tema.

Curioso, pero de poco valor científico, es el ensayo de F. L. T. Talasolambros In defense of Thucydides, Atenas 1979, que es un alegato contra los que buscan «errores» en su obra.

Hay que mencionar, finalmente, el Historical Commentary on Thucydides, de Gomme (Oxford 1959), que su autor no pudo concluir.

José ALSINA 